\title{
The IL-1 receptor and Rho directly associate to drive cell activation in inflammation
}

\author{
R. Singh, ${ }^{1}$ B. Wang, ${ }^{2}$ A. Shirvaikar, ${ }^{2}$ S. Khan, ${ }^{2}$ S. Kamat, ${ }^{2}$ J.R. Schelling, ${ }^{2}$ \\ M. Konieczkowski, ${ }^{2}$ and J.R. Sedor ${ }^{2}$ \\ ${ }^{1}$ Department of Medicine and Department of Physiology and Biophysics, School of Medicine, Case Western Reserve University , \\ Cleveland, Ohio 44106, USA \\ ${ }^{2}$ Rammelkamp Center for Research and Education, MetroHealth Medical Center, Cleveland, Ohio 44109-1998, USA
}

Address correspondence to: John R. Sedor, Department of Medicine, BG 531, MetroHealth Medical Center, 2500 MetroHealth Drive, Cleveland, Ohio 44109-1998, USA. Phone: (216) 459-4993; Fax: (216) 778-8248; E-mail:jrs4@po.cwru.edu.

Received for publication November 9, 1998, and accepted in revised form May 5, 1999.

IL-1-stimulated mesenchymal cells model molecular mechanisms of inflammation. Binding of IL-1 to the type I IL-1 receptor (IL-1R) clusters a multi-subunit signaling complex at focal adhesion complexes. Since Rho family GTPases coordinately organize actin cytoskeleton and signaling to regulate cell phenotype, we hypothesized that the IL-1R signaling complex contained these G proteins. IL-1 stimulated actin stress fiber formation in serum-starved HeLa cells in a Rho-dependent manner and rapidly activated nucleotide exchange on RhoA. Glutathione $S$-transferase (GST) fusion proteins, containing either the full-length IL-1R cytosolic domain (GST-IL-1Rcd) or the terminal 68 amino acids of IL-1R required for IL-1-dependent signal transduction, specifically coprecipitated both RhoA and Rac-1, but not $\mathrm{p} 21^{\text {ras }}$, from Triton-soluble HeLa cell extracts. In whole cells, a small-molecular-weight $\mathrm{G}$ protein coimmunoprecipitated by anti-IL-1R antibody was a substrate for C3 transferase, which specifically ADP-ribosylates Rho GTPases. Constitutively activated RhoA, loaded with $\left[\gamma-{ }^{32} \mathrm{P}\right] \mathrm{GTP}$, directly interacted with GST-IL-1Rcd in a filter-binding assay. The IL-1Rcd-RhoA interaction was functionally important, since a dominant inhibitory mutant of RhoA prevented IL-1Rcd-directed transcriptional activation of the IL- 6 gene. Consistent with our previous data demonstrating that IL-1R-associated myelin basic protein (MBP) kinases are necessary for IL-1-directed gene expression, cellular incorporation of C3 transferase inhibited IL-1R-associated MBP kinase activity both in solution and in gel kinase assays. In summary, IL-1 activated RhoA, which was physically associated with IL-1Rcd and necessary for activation of cytosolic nuclear signaling pathways. These findings suggest that IL-1-stimulated, Rhodependent cytoskeletal reorganization may cluster signaling molecules in specific architectures that are necessary for persistent cell activation in chronic inflammatory disease.

J. Clin. Invest. 103:1561-1570 (1999).

\section{Introduction}

IL-1 is a pivotal proinflammatory cytokine implicated in the pathogenesis of sepsis, septic shock, and tissue inflammation (1). IL-1-mediated signal transduction requires expression of the type I IL-1 receptor (IL-1R), an $80-\mathrm{kDa}$ transmembrane receptor present on all cell types (2-4). Although the biological activities of IL-1 are well characterized, the cytosolic signaling pathways activated by the IL-1-IL-1R interaction remain incompletely defined. IL-1R is a multi-subunit complex. An IL-1R accessory protein (IL-1RAcP) increases the binding affinity of IL-1 for IL-1R (5), similar to the non-ligand-binding subunits of the hematopoietic cytokines, and is necessary for IL-1-activated signaling $(6,7)$. We and others have demonstrated that multiple serine/threonine protein kinases directly associate with the IL-1R cytosolic domain and are required for gene transcription (8). Two of these serine/threonine kinases, IRAK and IRAK-2, have been identified $(9,10)$, and both stimulate downstream signal transduction cascades that culminate in activation of target gene transcription.

However, a linear description of an IL-1-stimulated signaling cascade underestimates the combinatorial com- plexity of signaling pathways that are activated at the cellular level in disease pathogenesis. For example, alterations in extracellular matrix abundance and composition characterize chronic inflammatory diseases. Perhaps by changing cell shape, matrix regulates or restricts the specific signaling and gene transcription pathways that are activated by soluble extracellular molecules $(11,12)$. Cell-matrix interactions and IL-1-dependent signaling pathways collaborate to regulate target cell function. IL1 receptors cluster at focal adhesions (13), and IL-1 stimulates rapid phosphorylation of talin, a structural component of focal complexes, as well as the activation of focal adhesion kinase p125FAK $(14,15)$. Mesenchymal cell adhesion to fibronectin regulates IL-1-dependent inhibition of proteoglycan synthesis, stimulation of nuclear factor- $\mathrm{KB}(\mathrm{NF}-\mathrm{\kappa B})$ activity, and induction of collagen and IL-6 gene expression (16-18). IL-1-induced calcium flux in fibroblasts and chondrocytes is dependent on attachment to matrix and formation of focal adhesions $(15,19)$. Together, these studies indicate that IL1 -activated cytosolic and nuclear signaling pathways require appropriate assembly of cell-matrix adhesion complexes and organization of actin cytoskeleton. 
The Rho family of small GTPases - RhoA, Rac-1, and Cdc42 - controls actin cytoskeleton organization and assembly of associated adhesion complexes $(20,21)$. Rho GTPases also regulate signal transduction cascades that direct activities of different transcription factors $(21,22)$ known to be stimulated by IL-1. Although no specific $\mathrm{G}$ protein has been linked to the IL-1R complex, IL-1 does stimulate membrane GTPase activity (23). Given the dependence of IL-1 signal transduction on actin stress fiber and focal adhesion assembly, we hypothesized that Rho family GTPases are components of the IL-1R signaling complex and that they function as molecular switches to coordinate cytoskeletal reorganization and the activation of downstream signaling cascades.

\section{Methods}

Cell culture. HeLa cells and human embryonic kidney 293 cells were cultured in RPMI-1640 media (GIBCO BRL, Gaithersburg, Maryland, USA) supplemented with $2 \mathrm{mM}$ glutamine (GIBCO BRL), $15 \mathrm{mM}$ HEPES, $100 \mathrm{U} / \mathrm{mL}$ penicillin, 100 $\mu \mathrm{g} / \mathrm{mL}$ streptomycin, $0.25 \mu \mathrm{g} / \mathrm{mL}$ fungizone, $5 \mu \mathrm{g} / \mathrm{mL}$ insulin and transferrin, $5 \mathrm{ng} / \mathrm{mL}$ sodium selenite, 10\% FBS (HyClone Laboratories, Logan, Utah, USA), and $10 \%$ calf bovine serum (HyClone Laboratories) at $37^{\circ} \mathrm{C}$ in $5 \% \mathrm{CO}_{2}$.

Actin stress fiber assembly. HeLa cells were either controlscraped or scrape-loaded with C3 transferase as described below. Cells were plated on glass coverslips (Bellco Glass, Vineland, New Jersey, USA) and maintained in serum-free RPMI media for 18 hours prior to stimulation for 10 minutes with either vehicle or IL-1 $\alpha(20 \mathrm{ng} / \mathrm{mL})$. Cells were washed with PBS and fixed in $4 \%$ paraformaldehyde for 20 minutes at $4^{\circ} \mathrm{C}$. Fixed cells were permeabilized for 10 minutes with $0.2 \%$ Triton $\mathrm{X}-100$ in PBS. To view filamentous actin, cells were then incubated for 30 minutes with rhodamine isothiocyanate-conjugated phalloidin (Molecular Probes Inc., Eugene, Oregon, USA). Cells were analyzed with an Olympus BH-2 fluorescent microscope, and random fields $(n=10)$ for each experimental condition were photographed at $\times 100$ with Ilford XP2 400 film.

Scrape-loading of botulinum C3 toxin into HeLa cells. Recombinant botulinum C3 ADP-ribosyltransferase (Calbiochem-Novabiochem Corp., San Diego, California, USA) was introduced into HeLa cells by scrape-loading as described (24). Confluent HeLa cells grown in 100-mm dishes were washed first in $5 \mathrm{~mL}$ of PBS and then twice with $2 \mathrm{~mL}$ of scraping buffer $(114 \mathrm{mM} \mathrm{KCl}$, $15 \mathrm{mM} \mathrm{NaCl}, 5.5 \mathrm{mM} \mathrm{MgCl}_{2}$, and $10 \mathrm{mM}$ Tris- $\mathrm{HCl}$ [pH 7.0]). Scraping buffer $(0.5 \mathrm{~mL} / \mathrm{dish})$ was then added in the absence or presence of C3 transferase $(5-10 \mu \mathrm{g} / \mathrm{mL})$. Cells were gently scraped, resuspended in RPMI media containing $10 \%$ FBS, and split into 3 (100-mm) dishes. Cells were allowed to recover overnight before serum deprivation. The ADP-ribosylation state of Rho after cellular incorporation of C3 transferase was determined by assaying cell extracts for residual Rho available for ADP-ribosylation, with excess transferase as described (25).

Measurement of guanine nucleotide accumulation on RhoA. HeLa cells were rendered quiescent by culturing for 18 hours in RPMI media supplemented with $0.1 \%$ FBS. Quiescent cells were washed in $\mathrm{Ca}^{2+}$ - and $\mathrm{Mg}^{2+}$-free Dulbecco's PBS, and labeled with $\left[{ }^{32} \mathrm{P}\right.$ ]orthophosphate $(700 \mu \mathrm{Ci} / \mathrm{mL})$ for 4 hours in phosphatefree DMEM (GIBCO BRL) supplemented with $0.25 \%$ dialyzed FBS. Cells were washed in RPMI media supplemented with $0.1 \%$ FBS containing either vehicle or human recombinant IL-100 (Hoffman-LaRoche, Nutley, New Jersey, USA) at a final concentration of $(20 \mathrm{ng} / \mathrm{mL})$, for the times indicated in Figure 3. HeLa cells were then lysed on ice in buffer containing 100 mM HEPES ( $\mathrm{pH}$ 7.4), $2 \%$ Triton $\mathrm{X}-100,1 \%$ deoxycholate, $0.1 \%$ SDS, $300 \mathrm{mM} \mathrm{NaCl}, 10 \mathrm{mM} \mathrm{MgCl} 2,2 \mathrm{mM}$ EGTA, $2 \mathrm{mg} / \mathrm{mL}$ a

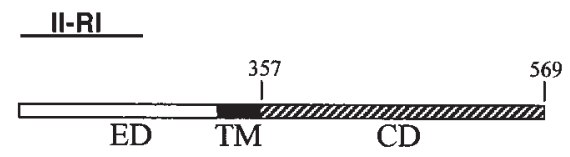

b

Fusion protein constructs

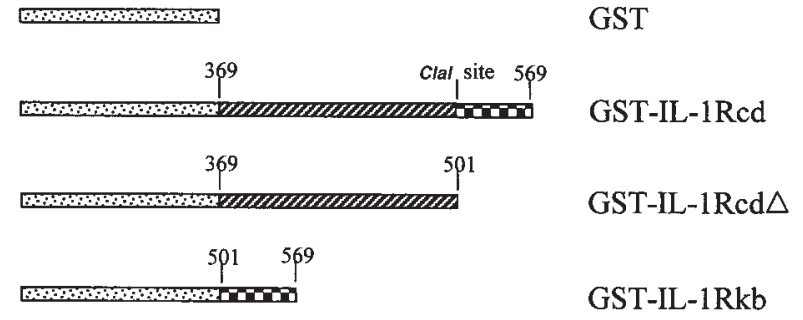

\section{Figure 1}

GST-IL-1Rcd fusion proteins. A series of GST-IL-1R fusion proteins were purified from E. coli as described in Methods. (a) The full-length, 569 -amino acid human IL-1R is shown for reference. The mature singletransmembrane protein is 552 amino acids. The extracellular domain (open region, ED), including a 17-amino acid signal peptide, spans the amino acids from 1 to 336; the transmembrane region (filled region, TM) from 337 to 357; and the cytosolic domain (hatched region, CD) from 358 to 569. (b) GST and GST-IL-1R fusion proteins are shown. GST-IL1 Rcd contains amino acids $369-569$ of IL-1Rcd, fused to GST. The Clal site in the IL-1Rcd cDNA sequence, used to remove the sequences encoding the $\mathrm{COOH}$-terminal amino acid residues required for downstream signaling, is indicated. The resulting fusion protein, GST-IL- 1 Rcd $\Delta$, contains membrane-proximal cytosolic domain region amino acids 369-501 fused to GST. GST-IL-1Rkb contains the $\mathrm{COOH}$-terminus signaling domain (amino acids 501-569), and its construction is described in Methods.

BSA, $1 \mathrm{mM}$ sodium orthovanadate, $1.2 \mu \mathrm{g} / \mathrm{mL}$ leupeptin, 1.2 $\mu \mathrm{g} / \mathrm{mL}$ pepstatin, and $120 \mu \mathrm{M}$ phenylmethylsulfonyl fluoride as described (26). Lysates were centrifuged at $14,000 \mathrm{~g}$ for $5 \mathrm{~min}$ utes to sediment nuclei, and supernatants were adjusted to 500 $\mathrm{mM} \mathrm{NaCl}$. After preclearing for 30 minutes with protein ASepharose (Pharmacia Biotech Inc., Piscataway, New Jersey, USA), RhoA was immunoprecipitated with $4 \mu \mathrm{g}$ of rabbit polyclonal anti-RhoA (Santa Cruz Biotechnology Inc., Santa Cruz, California, USA) for 60 minutes at $4^{\circ} \mathrm{C}$, followed by incubation with protein A-Sepharose for 2 hours. The immune complexes were washed 5 times in $50 \mathrm{mM}$ HEPES ( $\mathrm{pH} 7.4$ ), $500 \mathrm{mM} \mathrm{NaCl}$, $0.1 \%$ Triton X-100, and $0.005 \%$ SDS. The $\left[{ }^{32} \mathrm{P}\right]$ orthophosphatelabeled nucleotides were eluted in $5 \mathrm{mM}$ EDTA, $2 \mathrm{mM}$ DTT, $0.2 \%$ SDS, $0.5 \mathrm{mM} \mathrm{GTP}$, and $0.5 \mathrm{mM}$ GDP for 20 minutes at $68^{\circ} \mathrm{C}$. Nucleotides were separated by TLC on polyethylenimine cellulose plates (Selecto Scientific, Norcross, Georgia, USA) run in $1 \mathrm{M} \mathrm{KH}_{2} \mathrm{PO}_{4}$ (pH 3.4). Positions of unlabeled GDP and GTP standards (Sigma Chemical Co., St. Louis, Missouri, USA) were viewed under 254-nm ultraviolet light. After autoradiography, radiolabeled nucleotides were quantitated by scanning densitometry as described (27).

GST-IL-1R fusion proteins. The cytosolic domain (cd) of IL-1R was amplified by RT-PCR from HeLa cell RNA and subcloned into pGEX4T (Pharmacia Biotech Inc.), as published previously (8), to generate a series of GST-IL-1R expression constructs (Figure 1). The GEX4T-IL-1Rcd plasmid contains the fulllength cytosolic domain of IL-1R (amino acids 369-569); pGEX4T-IL-1R $\Delta$ consists of a 400-bp fragment encoding the membrane-proximal region (amino acids 369-501). The sequence encoding the $\mathrm{COOH}$-terminal amino acid residues 
that are required for NF- $\mathrm{KB}$ activation (amino acids 501-569) was released from pGEX-4T-IL-1Rcd using the restriction endonucleases ClaI and SalI, and directionally subcloned into pGEX-4T to generate $\mathrm{PGEX}-4 \mathrm{~T}-\mathrm{IL}-1 \mathrm{Rkb}$. The reading frame of the GST-IL-1R expression vector junction sequences was confirmed by dideoxy DNA sequencing. After transformation into BL21 Escherichia coli, bacterial clones were screened for expression of isopropyl- $\beta$-thiogalactoside-inducible GST fusion proteins with the predicted relative molecular masses.

Recombinant protein production. Expression and purification of the GST fusion proteins were performed as described (8). For the protein-protein interaction filter-binding assays (see below), GST and GST fusion proteins were eluted from GSHSepharose beads by incubation with an equal volume of freshly prepared release buffer (50 mM Tris- $\mathrm{HCl}$ [pH 8.0], $150 \mathrm{mM}$ $\mathrm{NaCl}, 5 \mathrm{mM} \mathrm{MgCl}_{2}$, and $1 \mathrm{mM}$ DTT) containing $15 \mathrm{mM}$ reduced glutathione (Sigma Chemical Co.) (28). After incubation in release buffer for 20 minutes at $4^{\circ} \mathrm{C}$, the beads were pelleted and the supernatant removed. The procedure was repeat$\mathrm{ed}$, and the supernatants were pooled and dialyzed overnight against $2 \mathrm{~L}$ of $10 \mathrm{mM}$ Tris- $\mathrm{HCl}$ ( $\mathrm{pH}$ 7.6), $10 \mathrm{mM} \mathrm{NaCl}, 2 \mathrm{mM}$ $\mathrm{MgCl}_{2}$, and $0.1 \mathrm{mM} \mathrm{DTT}$, with 2 changes of buffer. Eluted proteins were concentrated in a Centricon-10 (Amicon Inc., Beverly, Massachusetts, USA) filter device by centrifugation in a fixed-angle rotor at 7,000 $\mathrm{g}$. GST fusion proteins and GST integrity were analyzed on Coomassie blue-stained SDS-polyacrylamide gels, and the protein concentration was estimated by comparison with known concentrations of BSA.

Immunoblot analysis. HeLa cells were rendered quiescent and Triton X-100 cell lysates prepared as described previously (8). Cell extracts, precleared with GST and GSH-Sepharose as described above, were incubated with 5-10 $\mu$ g of GST, GST-IL-1Rcd, GSTIL-1Rcd $\Delta$, or GST-IL-1Rkb proteins. The beads were collected by centrifugation, washed 3 times with NET buffer $(150 \mathrm{mM} \mathrm{NaCl}$, $5 \mathrm{mM}$ EDTA, $50 \mathrm{mM}$ Tris- $\mathrm{HCl}$ [pH 8.0], and 0.05\% NP-40), and boiled for 5 minutes with $1 \times$ SDS-Laemmli loading buffer. Proteins were resolved on $12 \%$ SDS-polyacrylamide gels. Separated proteins were transferred to nitrocellulose membranes (Schleicher and Schuell Inc., Keene, New Hampshire, USA) and subjected to Western blot analysis. The following antibodies were obtained from Santa Cruz Biotechnology: polyclonal anti-RhoA (directed against an internal domain of RhoA p21); polyclonal anti-Rac-1 (directed against the $\mathrm{COOH}$-terminal 14 amino acids); and monoclonal anti-H-Ras (directed against amino acids 63-73), which also recognizes epitopes of $\mathrm{K}$ - and $\mathrm{N}$-Ras. The antibodies were viewed using a chemiluminescence detection system (ECL; Du Pont NEN Research Products, Boston, Massachusetts, USA) as described previously (27).
[32P]NAD-ribosylation of HeLa cell membrane proteins. HeLa cell membranes were [ $\left.{ }^{32} \mathrm{P}\right] \mathrm{ADP}$-ribosylated by $\mathrm{C} 3$ transferase as described previously (29). Briefly, quiescent HeLa cells were stimulated with IL-1 $\alpha(20 \mu \mathrm{g} / \mathrm{mL})$ for 10 minutes, washed twice in ice-cold PBS, scraped from plates, and centrifuged at $1,800 \mathrm{~g}$ at $4^{\circ} \mathrm{C}$ for 5 minutes. Cells were resuspended in $1 \mathrm{~mL}$ of ice-cold TMSDE buffer (50 mM Tris [pH 7.6], $75 \mathrm{mM}$ sucrose, $6 \mathrm{mM}$ $\mathrm{MgCl}_{2}, 1 \mathrm{mM}$ DTT, $1 \mathrm{mM}$ EDTA, $1.2 \mu \mathrm{g} / \mathrm{mL}$ leupeptin, 1.2 $\mu \mathrm{g} / \mathrm{mL}$ pepstatin, and $120 \mu \mathrm{M}$ PMSF), and incubated at $4^{\circ} \mathrm{C}$ for 10 minutes. To disrupt cell membranes, HeLa cells were frozen at $-70^{\circ} \mathrm{C}$ and then thawed. Broken cells were homogenized using a Dounce tissue grinder on ice, and the particulate suspension was centrifuged at $20,000 \mathrm{~g}$ at $4^{\circ} \mathrm{C}$ for 30 minutes. Pellets containing the membrane fraction were then resuspended in $0.2 \mathrm{~mL}$ of TMSDE buffer, and protein concentrations were quantitated using the assay from Bio-Rad Laboratories Inc. (Hercules, California, USA) standardized against a BSA standard curve. HeLa cell membranes $(200 \mu \mathrm{g})$ were $\left[{ }^{32} \mathrm{P}\right]$ NAD-ribosylated by C 3 transferase for 60 minutes at $37^{\circ} \mathrm{C}$ in $200 \mu \mathrm{L}$ of reaction buffer containing $50 \mathrm{mM}$ triethanolamine $\mathrm{HCl}(\mathrm{pH}$ 7.4), 2 mM EDTA, 1 mM DTT, 0.5 mM ATP, $2.5 \mathrm{mM} \mathrm{MgCl}_{2}, 10$ $\mathrm{mM}$ thymidine, $0.2 \%$ Triton $\mathrm{X}-100,\left[\alpha-{ }^{32} \mathrm{P}\right] \mathrm{NAD}(1 \mu \mathrm{Ci} /$ tube, $1,000 \mathrm{Ci} / \mathrm{mM}$; Amersham Life Sciences Inc., Arlington Heights, Illinois, USA), and 4-5 $\mu \mathrm{g}$ purified recombinant $\mathrm{C} 3$ transferase. To determine total ADP-ribosylation of Rho proteins, reactions were terminated by the addition of $4 \times$ Laemmli sample buffer and boiled for 5 minutes. For immunoprecipitation of membrane and IL-1R-associated Rho GTPases, reactions were terminated by addition of $600 \mu \mathrm{L}$ of HTG lysis buffer $(20 \mathrm{mM}$ HEPES [pH 7.2], 1\% Triton X-100, 10\% glycerol, $20 \mathrm{mM} \mathrm{NaF}, 1$ $\mathrm{mM} \mathrm{Na}_{3} \mathrm{VO}_{4}, 1.2 \mu \mathrm{g} / \mathrm{mL}$ leupeptin, $1.2 \mu \mathrm{g} / \mathrm{mL}$ pepstatin, and $120 \mu \mathrm{M}$ PMSF). Membranes were incubated at $4^{\circ} \mathrm{C}$ for $60 \mathrm{~min}-$ utes. Lysates were clarified at $4^{\circ} \mathrm{C}$ by 5 minutes of centrifugation at $13,000 \mathrm{~g}$ and incubated with primary antibodies. IL-1R was immunoprecipitated using a rabbit polyclonal antibody raised against a peptide corresponding to amino acids 550-569 of IL-1R (Santa Cruz Biotechnology). GTP-binding proteins HRas, Rac-1, and RhoA were immunoprecipitated with the antibodies described above. Immune complexes were captured by the addition of Gamma-Bind (Pharmacia Biotech Inc.), and the proteins were resolved on a $12.5 \%$ SDS-polyacrylamide gel. Radiolabeled proteins were detected by autoradiography.

Filter-binding assay for protein-protein interactions. Protein-protein interactions between IL-1R and RhoA were determined in vitro using a dot blot filter-binding assay as described previously $(30,31)$. Briefly, $10 \mu \mathrm{g}$ of GST, recombinant Rho GTPaseactivating protein (GST-RhoGAP), GST-IL-1Rcd, and BSA were spotted onto nitrocellulose (BA 83; Schleicher and Schuell Inc.)
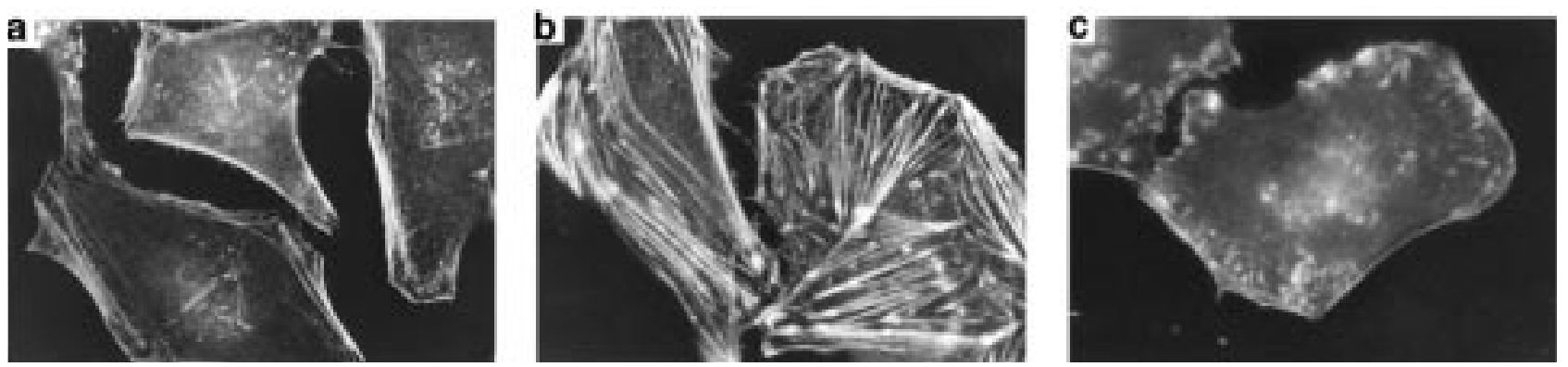

Figure 2

RhoA is necessary for IL-1-mediated actin stress fiber formation. Control-scraped HeLa cells and cells scrape-loaded in the presence of C3 transferase were plated on coverslips and allowed to recover for 12 hours, as described in Methods. Serum-starved cells were stimulated with or without IL-1 $\alpha$ for 10 minutes, and actin stress fibers were viewed by rhodamine-conjugated phalloidin. (a) Few actin stress fibers were seen in vehicle-stimulated HeLa cells. (b) Cells stimulated with IL-1 organize actin stress fibers. (c) In contrast, IL-1 failed to stimulate stress fiber formation in HeLa cells previously scrape-loaded with C3 transferase. Each photomicrograph is representative of a blinded evaluation of photographs taken from 10 fields for each condition from 4 separate experiments. 


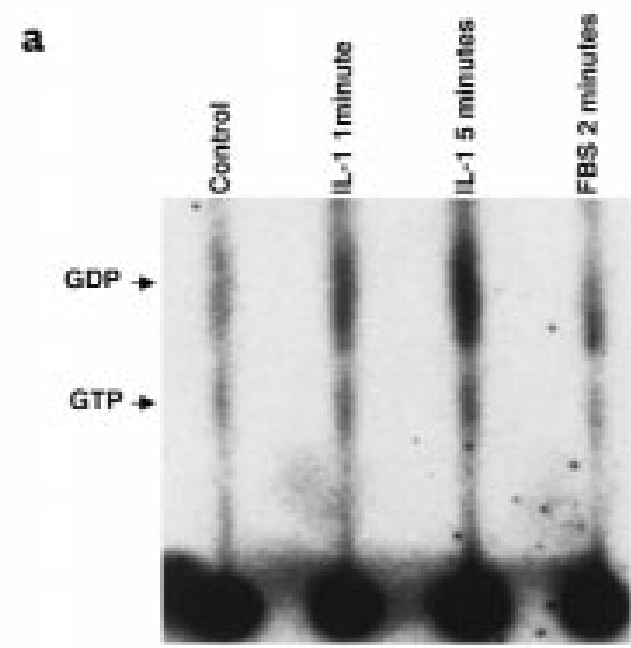

b

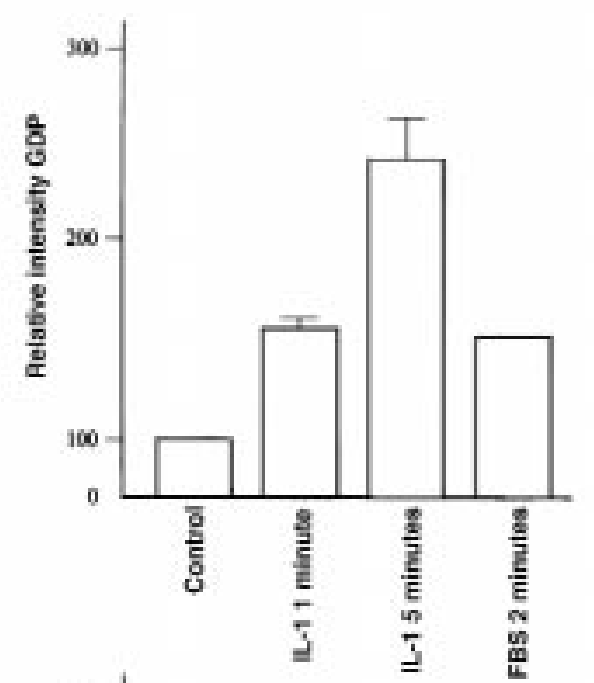

c

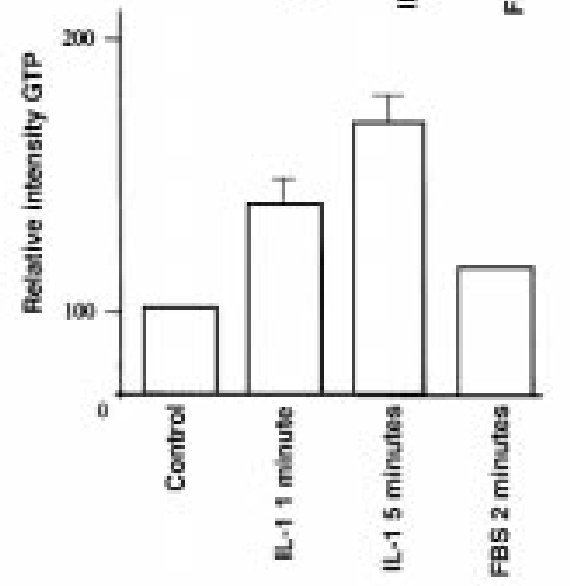

\section{Figure 3}

IL-1 activates RhoA nucleotide exchange. HeLa cells were rendered quiescent for 18 hours and then labeled with [ $\left.{ }^{32} \mathrm{P}\right]$ orthophosphate (700 $\mu \mathrm{Ci} / \mathrm{mL}$ ) for 4 hours. Cells were stimulated with vehicle, with IL- $1 \alpha$ for 1 minute or 5 minutes, or with $10 \%$ FBS for 2 minutes. The cells were lysed and RhoA was immunoprecipitated. The [ $\left.{ }^{32} \mathrm{P}\right] \mathrm{GTP}$ and $\left[{ }^{32} \mathrm{P}\right] \mathrm{GDP}$ associated with RhoA were eluted, separated by TLC, and viewed by autoradiography (a) as described in Methods. Positions of unlabeled GTP and GDP standards, viewed under 254-nm ultraviolet light, are indicated at left. After autoradiography, changes in GDP (b) and GTP (c) bound to immunoprecipitated RhoA were quantified by scanning densitometry. The results are representative of 3 independent experiments. using a Bio-Rad dot blot apparatus. The pGEX-2T vector expressing the catalytic domain of RhoGAP was a kind gift from Alan Hall (Medical Research Council Laboratory for Molecular Cell Biology, CRC Oncogene and Signal Transduction Group, University College of London, London, United Kingdom). The membrane was blocked for 2 hours at room temperature with 5\% nonfat milk in PBS. Recombinant RhoA (1 $\mu \mathrm{g})$, with an activating glycine $\rightarrow$ valine substitution at codon 14 (V14RhoA; gift of Alan Hall), was expressed as a GST fusion protein. V14RhoA was preloaded for 10 minutes at $30^{\circ} \mathrm{C}$ with $10 \mu \mathrm{Ci}\left[\gamma_{-}{ }^{32} \mathrm{P}\right] \mathrm{GTP}(6,000 \mathrm{Ci} / \mathrm{mM}$; Du Pont NEN Research Products) in $30 \mu \mathrm{L}$ of $50 \mathrm{mM}$ Tris- $\mathrm{HCl}$ (pH 7.5), $5 \mathrm{mM}$ EDTA, and $0.5 \mathrm{mg} / \mathrm{mL}$ BSA. Nucleotide exchange was stopped on ice by the addition of $10 \mathrm{mM} \mathrm{MgCl}_{2}$, and free nucleotide was removed by filtration through a microcentrifuge filter unit (Ultrafree, NMCL 10,000; Millipore Corp., Bedford, Massachusetts, USA). The nitrocellulose membrane was washed twice with buffer A (50 mM Tris-HCl [pH 7.5], 100 mM NaCl, 5 mM MgCl $2,0.1$ $\mathrm{mM}$ DTT) and then incubated in $3 \mathrm{~mL}$ of buffer A containing $1 \mathrm{mM}$ GTP, $1 \mathrm{mg} / \mathrm{mL}$ BSA, and the $\left[\gamma^{32} \mathrm{P}\right] \mathrm{GTP}-$ bound V14RhoA. After incubation for 5 minutes on ice, the membrane was washed 3 times with ice-cold PBS supplemented with $0.1 \%$ Tween-20, and autoradiographed to view the bound GTPase. After autoradiography, $\left[\gamma^{-32} \mathrm{P}\right] \mathrm{GTP}-\mathrm{V} 14 \mathrm{RhoA}$ bound to GST, GST-RhoGAP, and GST-IL-1Rcd was quantified by liquid scintillation counting.

Transient transfection and chloramphenicol acetyltransferase assays. As we have described previously, 293 cells stably expressing the EBNA-1 protein were cotransfected with calcium phosphate/DNA coprecipitates containing a reporter plasmid. The reporter plasmid was composed of IL-6 5' flanking region (-742 to $+11 \mathrm{bp}$ ), fused to either the chloramphenicol acetyltransferase (CAT) IL-6-CAT, IL-1Rcd eukaryotic expression vector pEBVHisIL-1Rcd, or the control plasmid pEBVHisLacZ; and, as indicated, the dominant-negative mutant expression constructs of RhoA (pCMV5-N19RhoA) or Rac-1 (pEXV-N17Rac$1)$. The indicated expression constructs (10 $\mu \mathrm{g}$ each) were applied to cells $\left(5 \times 10^{5}\right)$ cultured for 48 hours in $100-\mathrm{mm}$ dishes. Plasmids pEBVHisIL-1Rcd, pEBVHisLacZ, and IL-6-CAT, a generous gift from Jan Vilcek (New York University Medical Center, New York, New York, USA), have been described previously (8). Dominant-negative constructs of RhoA and Rac-1 contain a serine $\rightarrow$ asparagine or a threonine $\rightarrow$ asparagine substitution at amino acids 19 and 17, respectively. Both mutants preferentially bind GDP, maintaining the GTPases in an inactive state. The plasmid pCMV5-N19RhoA was kindly provided by Martin A. Schwartz (Department of Vascular Biology, The Scripps Research Institute, La Jolla, California, USA) (32). Cells were harvested 72 hours after transfection, and CAT activity in cell extracts was determined by liquid scintillation quantification of $\left[{ }^{14} \mathrm{C}\right] n$-butyryl chloramphenicol.

Fusion protein solution kinase assay. Cell extracts were prepared from quiescent HeLa cells as described above. Prior to preclearing, lysates were incubated with or without $5 \mu \mathrm{g}$ of $\mathrm{C} 3$ exoenzyme (Calbiochem-Novabiochem Corp.) for 15 minutes at $30^{\circ} \mathrm{C}$. Clarified lysates were then incubated overnight with 5-10 $\mu \mathrm{g}$ GST, GST-IL-1Rcd, GST-IL-1Rcd $\Delta$, or GST-IL-1Rkb proteins at $4^{\circ} \mathrm{C}$. The beads were collected by centrifugation, washed 3 times with NET buffer, twice with kinase buffer $(100 \mathrm{mM} \mathrm{NaCl}, 20$ mM HEPES [pH 7.0], $5 \mathrm{mM} \mathrm{MgCl}$, and $5 \mathrm{mM} \mathrm{MnCl}_{2}$ ), and then used in in vitro solution kinase assays with myelin basic protein (MBP) as substrate, as described previously (8).

Solid-phase (in-gel) kinase assays. Solid-phase kinase assays were performed as we have described previously (8). Briefly, cells that had been scrape-loaded in the absence or presence of C3 transferase were stimulated with IL- $1 \alpha(20 \mathrm{ng} / \mathrm{mL})$. Cells were lysed in $20 \mathrm{mM}$ Tris- $\mathrm{HCl}$ (pH 7.4), 3 mM MgCl $2,1 \mathrm{mM}$ EGTA, $1 \mathrm{mM}$ DTT, $1 \%$ Triton X-100, $1.2 \mu \mathrm{g} / \mathrm{mL}$ leupeptin, $1.2 \mu \mathrm{g} / \mathrm{mL}$ 

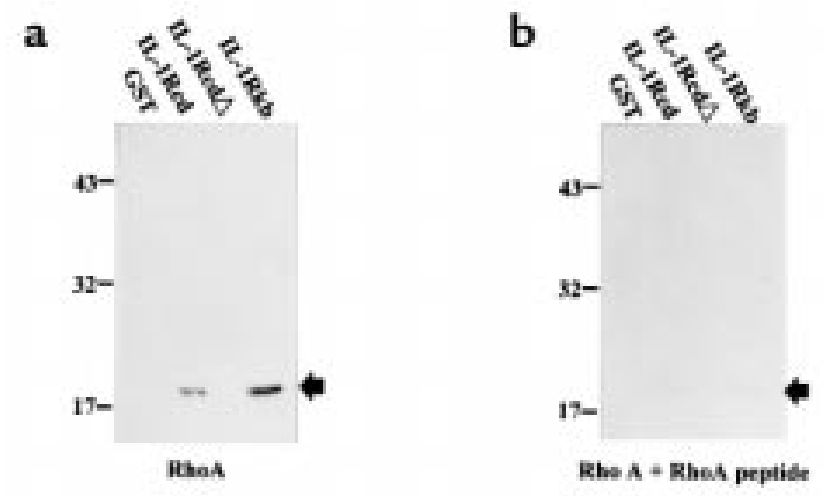

c

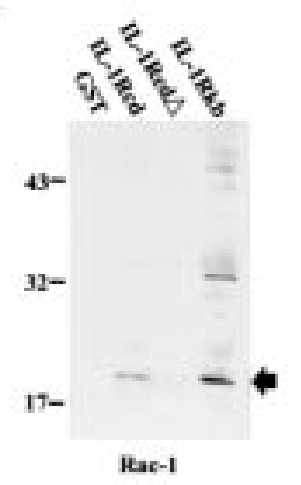

d

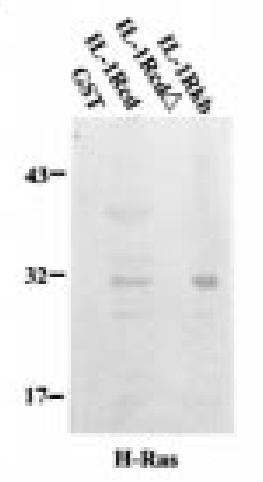

Figure 4

GST-IL-1R fusion proteins precipitate RhoA and Rac-1 GTPases from HeLa cell extracts. Proteins coprecipitated by GST-IL-1R fusion proteins from HeLa cell lysates were analyzed by immunoblotting for Rho GTPases, as described in Methods. Proteins were resolved by SDS-PAGE. Molecular mass markers (in $\mathrm{kDa}$ ) are indicated at left, and the position of GST-IL-1R-associated Rho GTPase is indicated by an arrow at the bottom right of each panel. GST-IL-1Rcd fusion proteins specifically associate with Rho family GTPases RhoA (a) and Rac-1 (c), but not H-Ras (d). RhoA associated with GST-IL-1Rcd fusion proteins is blocked by preincubation of the RhoA antibody with the RhoA peptide immunogen (b). Results are representative of 4 independent experiments.

pepstatin, and $120 \mu \mathrm{M}$ PMSF. Precleared cell lysates were then incubated at $4^{\circ} \mathrm{C}$ for 30-60 minutes with IL-1R antibody. Protein A-associated IL-1R immune complexes were collected by centrifugation and washed 3 times with NET buffer. IL-1R immune complexes were resolved on $10 \%$ SDS-polyacrylamide gels copolymerized with $0.1 \mathrm{mg} / \mathrm{mL} \mathrm{MBP}$. The gels were then subjected to an in-gel kinase assay, and proteins were viewed by autoradiography.

\section{Results}

RhoA is necessary for IL-1-mediated actin stress fiber formation. IL-1-activated signaling pathways require appropriate assembly of actin stress fibers and focal adhesion complexes. We first asked whether IL-1 stimulation of target cells actually reorganized the actin cytoskeleton. Actin stress fibers were labeled with rhodamine-conjugated phalloidin and viewed by immunofluorescence as described in Methods. Serum-starved and vehicle-stimulated HeLa cells had very few stress fibers but displayed a punctate distribution of filamentous actin on the plasma membrane (Figure 2a). Within 5 minutes after the addi-

tion of IL-1 (20 ng/mL), actin began to reorganize, with a loss of punctate actin and an increase in actin filament organization (not shown). By the 10-minute point, IL1-stimulated HeLa cells contained numerous densely packed stress fibers lying parallel to the plasma membrane (Figure 2b). The small GTPase-binding protein RhoA regulates the formation of actin stress fibers and focal adhesion plaques (33). To investigate the role of Rho GTPases in coordinating IL-1-stimulated cytoskeletal reorganization, HeLa cells were either control-scraped or scrape-loaded with the exoenzyme C3 transferase from Clostridium botulinum. This exoenzyme specifically inhibits Rho by ADP-ribosylation of amino acid Asn-41, which is located in a putative effector-binding domain. IL-1 did not stimulate actin stress fiber formation in HeLa cells scrape-loaded with C3 transferase, although the cells remained well spread (Figure 2c). Control-scraped cells assembled actin stress fibers in response to IL-1 treatment (not shown). These results suggest that a Rho GTPase coordinates cytoskeletal rearrangements that are necessary for IL-1-mediated cell activation.

IL-1 stimulates RhoA activation. To determine whether Rho was activated by IL-1, we next analyzed accumulation of radioactive guanine nucleotides on RhoA. HeLa cells labeled with [ $\left.{ }^{32} \mathrm{P}\right]$ orthophosphate were stimulated with vehicle or with IL-1 $\alpha$ for 1 minute or 5 minutes, and the activation state of RhoA was determined by analyzing RhoA-bound radioactive nucleotides by TLC (Figure 3). Within 1 minute, IL-1 stimulated nucleotide exchange on RhoA, as indicated by the increase in RhoA-bound [32P]GDP and [ $\left.{ }^{32} \mathrm{P}\right]$ GTP compared with vehicle-stimulated cells. Concordant with the time course of IL-1-stimulated actin stress fiber formation, Rho activity was further stimulated by approximately 2 - to 3 -fold after 5 minutes of IL-1 stimulation. Total RhoA immunoprecipitated was not influenced by IL-1 stimulation (not shown). RhoAassociated $\left.{ }^{32} \mathrm{P}\right] \mathrm{GDP}$, an inactive form of the molecule, was more abundant than RhoA-associated [ $\left.{ }^{32} \mathrm{P}\right] \mathrm{GTP}$. However, RhoA-associated GTP is difficult to assay in adherent cells because Rho has high intrinsic GTPase activity that is not blocked by the precipitating antibody (26). As published previously $(26,34)$, increases in RhoAassociated GTP indicate RhoA activation.

GST-IL-1R fusion proteins precipitate RhoA and Rac-1 GTPases from HeLa cell extracts. We next investigated whether RhoA was a component of the IL-1Rcd signaling complex, by determining whether IL-1R sequences recruited RhoA and other Rho family GTPases from HeLa cell lysates. GST and GST-IL-1R fusion proteins were incubated with Triton X-100 HeLa cell extracts, and the protein complexes were subsequently precipitated and then analyzed for RhoA, Rac-1, and H-Ras by immunoblotting as described in Methods. Both RhoA and Rac-1 specifically coprecipitated with GST-IL-1Rcd, but not with GST (Figure 4, $\mathrm{a}$ and c). GST-IL-1Rkb (amino acids 501-569), which contains sequences known to be required for downstream signal pathway activation, also coprecipitated with both RhoA and Rac-1. In contrast, GST-IL$1 \operatorname{Rcd} \Delta$, which does not contain amino acid residues that are implicated in IL-1-stimulated signaling pathways, did not recruit RhoA or Rac-1 from HeLa cell extracts. Both the RhoA and Rac-1 peptide immunogens blocked detec- 


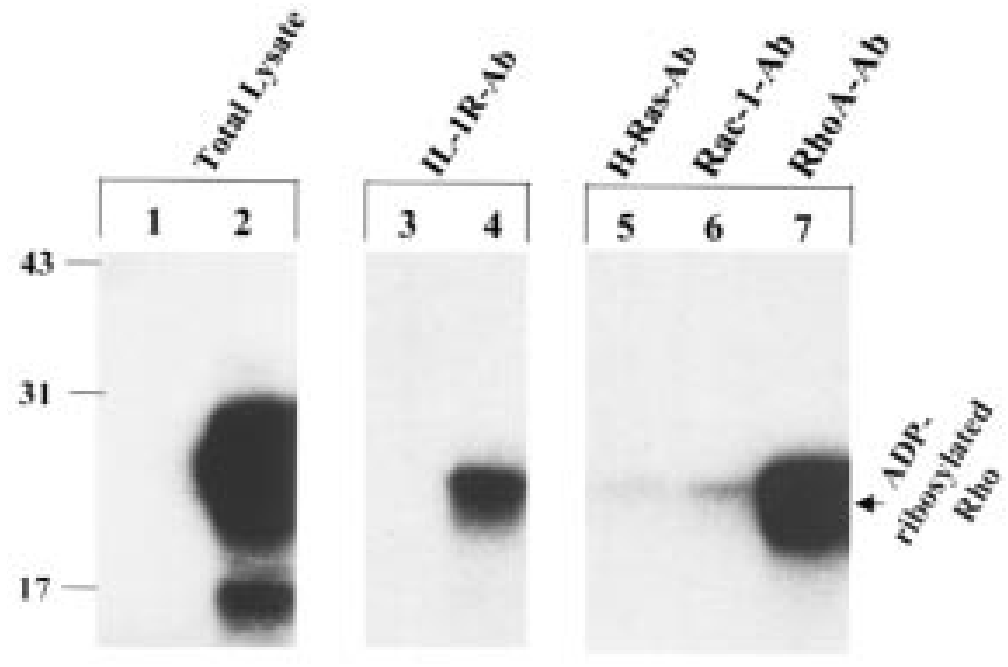

Figure 5

A substrate for C3 transferase coprecipitates with native IL-1R. Quiescent HeLa cells were stimulated with IL-1 $\alpha$ (20 ng/mL) for 10 minutes, and HeLa membranes were prepared as described in Methods. Membrane-associated Rho proteins in HeLa membranes were ADP-ribosylated in the presence $(+)$ or absence $(-)$ of C3 transferase and [ $\left.{ }^{32} \mathrm{P}\right]$ NAD. Ribosylated membrane extracts were used directly (Total lysate), or were subsequently analyzed by immunoprecipitation using an anti-IL-1R antibody (IL-1RAb) or specific small GTPase antibodies directed against H-Ras ( $\mathrm{H}$-Ras-Ab), Rac-1 (Rac-1-Ab), or RhoA (RhoA-Ab). Immunoprecipitated proteins were separated by SDS-PAGE, and [32P]NAD-ribosylated RhoA GTPases were viewed by autoradiography. The [ $\left.{ }^{32} \mathrm{P}\right]$ NAD-ribosylated Rho proteins are indicated by the arrow at right, and molecular mass markers (in kilodaltons) are shown at left. These autoradiographs are representative of 3 independent experiments. tion of IL-1R-associated RhoA (Figure 4b) and Rac-1 (not shown) by their respective antibodies, indicating that the immunoreactive bands were specific. GST-IL-1R fusion proteins specifically recruited Rho family GTPases. An HRas antibody, which recognizes epitopes common to $\mathrm{H}$-, $\mathrm{K}$ - and N-Ras, did not detect Ras in the IL-1Rcd fusion protein complexes (Figure 4d). The higher-molecularweight bands seen in Figure $4 d$ are nonspecific interactions between the anti-H-Ras antibody and either fulllength or truncated GST-IL-1R fusion proteins (not shown). These results indicate that the sequences contained in GST-IL-1Rcd specifically associate with the Rho GTPases RhoA and Rac-1, and that the COOH-terminal domain critical for IL-1-activated signaling is sufficient to coprecipitate these Rho family GTPases.

A substrate for $C 3$ transferase coprecipitates with native IL-1R. We next determined whether RhoA coimmunoprecipitated with native IL-1R expressed by HeLa cells. Previously, Rho GTPases coprecipitating with the PDGF receptor were labeled with $\left[{ }^{32} \mathrm{P}\right] \mathrm{NAD}$ using $\mathrm{C} 3$ transferase (29). We used a similar approach to identify Rho proteins in both HeLa cell membranes and IL-1R immune complexes. No radioactivity was associated with HeLa cell membranes that were incubated in reaction buffer that did not contain C3 transferase (Figure 5, lane 1). In contrast, [ $\left.{ }^{32} \mathrm{P}\right] \mathrm{ADP}$-ribosylated 21 - to $23-\mathrm{kDa}$ Rho proteins were readily demonstrated in HeLa cell membranes that were incubated in reaction buffer containing C3 transferase (Figure 5, lane 2). The identity of the radiolabeled protein as RhoA was confirmed by direct immunoprecipitation of RhoA by a specific rabbit polyclonal antibody (Figure 5, lane 7). As judged by the amount of radioactivity incorporated, RhoA is the predominant C3 substrate in HeLa cell membranes. An ADP-ribosylated 21-kDa protein coimmunoprecipitated with the IL-1R from HeLa cell membranes when incubated in the presence, but not the absence, of C3 transferase (Figure 5, lanes 3 and 4). The [ $\left.{ }^{32} \mathrm{P}\right]$ NAD-labeled RhoA immunoprecipitated by RhoA-specific antibodies comigrated with the [ $\left.{ }^{32} \mathrm{P}\right] \mathrm{NAD}-\mathrm{labeled} 21-\mathrm{kDa}$ Rho protein coprecipitated with IL-1R (Figure 5, lanes 4 and 7). Together, these data suggest that RhoA specifically asso- ciated with the native IL-1R expressed by HeLa cells. As expected, anti-Rac-1 and anti-H-Ras immunoprecipitates did not contain substrates for C 3 transferase-catalyzed ADP-ribosylation (Figure 5, lanes 5 and 6), further confirming the specificity of the exoenzyme for Rho protein substrates.

GST-IL-1Rcd directly interacts with RhoA in a filter-binding assay. We next assessed whether RhoA could directly associate with IL-1Rcd using a bacterially expressed GST fusion protein containing a constitutively activated RhoA mutant, V14RhoA. In contrast to wild-type RhoA, V14RhoA has low intrinsic GTPase activity, and after GDPGTP exchange, remains in an activated, GTP-bound state. V14RhoA loaded with $\left[\gamma^{-32} \mathrm{P}\right]$ GTP was incubated with nitrocellulose filters that had been spotted with GSTRhoGAP (which is known to bind to recombinant Rho in filter-binding assays), GST, GST-IL-1Rcd, or BSA. V14RhoA loaded with $\left[\gamma^{32} \mathrm{P}\right]$ GTP specifically bound to GST-IL-1Rcd and the positive control, GST-RhoGAP, but negligibly to GST, and not at all to BSA (Figure 6a). The amounts of $\left[\gamma^{-32} \mathrm{P}\right]$ GTP-V14RhoA associated with GST-IL1Rcd and GST-RhoGAP were similar, as determined by scintillation counting, and approximately 3- to 4-fold greater than the radioactivity nonspecifically associated with GST, a negative control (Figure 6b). No BSA-associated radioactivity was detected in any experiment, further confirming the specificity of the interaction between V14RhoA and GST-IL-1Rcd. From these results, we conclude that active RhoA can physically interact with amino acid sequences within the cytosolic domain of IL-1R.

Dominant-negative RhoA and Rac-1 repress IL-1Rcd-stimulated IL-6 gene transcription. Because appropriate cytoskeletal and focal adhesion assembly is necessary for IL-1-activated signaling, Rho activity should be necessary for IL-1-induced gene transcription. We have shown previously that IL-1Rcd overexpression stimulated CAT activity regulated by the $5^{\prime}$ IL-6 flanking region (8). A dominant-negative N19RhoA expression construct was transiently cotransfected with IL-6-CAT and pEBVHisIL$1 \mathrm{Rcd}$, or with control vector $\mathrm{pEBVHisLacZ}$, as described in Methods. As reported previously, ectopic expression of IL-1Rcd stimulated a 2.5- to 3-fold increase in transcrip- 
tion regulated by the IL- $65^{\prime}$ flanking region, compared with cells transfected with pEBVHisLacZ (Table 1). Expression of N19RhoA completely prevented the increase in CAT activity stimulated by IL-1Rcd overexpression, but had no effect in cells transfected with pEBVHisLacZ. Since GST-IL-1Rcd and GST-IL-1Rkb also precipitated Rac-1 from HeLa cell CAT activity, we also evaluated a dominant-negative Rac-1 expression construct (N17Rac-1) in this experimental system. Similar to N19RhoA, expression of N17Rac-1 completely prevented gene transcription that was stimulated by IL-1Rcd and regulated by the IL- $65^{\prime}$ flanking region. Taken together, these results suggest that RhoA and Rac-1 GTPases are required for IL-1-induced gene transcription.

$R$ ho is required for assembly and activation of $M B P$ kinases by IL-1Rcd. IL-1Rcd specifically associates with 63-, 83-, and 100-kDa MBP kinases, which stimulate IL-6-regulated CAT activity (8). Since RhoA is required for IL1Rcd-inducible IL- 6 transcription, we next investigated whether RhoA regulates the recruitment or activation of the IL-1Rcd-associated MBP kinases. HeLa cell lysates were treated with or without C3 transferase and then incubated with GST, GST-IL-1Rcd, or GST-IL-1Rkb in a solution kinase assay, as we have reported previously. Total MBP kinase activity coprecipitating with GST-IL1Rcd or GST-IL-1Rkb was significantly inhibited by C3 transferase pretreatment of HeLa cell lysates (Figure 7a, lanes 3 and 5) when compared with MBP kinase activity precipitated by the fusion proteins from control-treated HeLa extracts (Figure 7a, lanes 2 and 4). Using a solidphase (in-gel) kinase activity, we next determined which of the $3 \mathrm{MBP}$ kinases associated with the IL-1R signaling complex required Rho activity for recruitment and activation. HeLa cells were scrape-loaded with C3 transferase and stimulated with IL- $1 \alpha$ for 10 minutes, and IL-1R immune complexes were subjected to an in-gel kinase assay as described in Methods. Figure $7 \mathrm{~b}$ demonstrates the extent of RhoA ADP-ribosylation in HeLa cells scrapeloaded with C3 exoenzyme. Lysates prepared from control-scraped HeLa cells contain abundant RhoA available for ADP-ribosylation in an in vitro ribosylation reaction containing [ $\left.{ }^{32} \mathrm{P}\right] \mathrm{NAD}$ (Figure $7 \mathrm{~b}$, lane 1 ). In contrast, lysates from cells loaded with C3 transferase contain no residual Rho protein for further ADP-ribosylation (Figure $7 \mathrm{~b}$, lane 2 ). These data indicate that Rho proteins have been modified in situ by $\mathrm{C} 3$ transferase incorporated into HeLa cells and can no longer serve as a substrate for the excess transferase in the in vitro reaction. As we have reported previously, IL-1R immune complexes coprecipitate 63-, 83-, and 100-kDa MBP kinases from IL1-stimulated and IL-1-stimulated/control-scraped HeLa cells (Figure 7c, lane 1). In contrast, cellular incorporation of C3 transferase dramatically inhibited the activity of each of the MBP kinases (Figure 7c, lane 2), suggesting that functional Rho is required for recruitment and/or activation of these IL-1Rcd-associated kinases.

\section{Discussion}

Data from other laboratories have shown that productive IL-1 signal transduction in mesenchymal cells requires organization of actin into stress fibers and the assembly of focal adhesions. RhoA regulates actin polymerization and focal adhesion formation $(33,35)$. Our data suggest that (a) interaction of IL-1 with IL$1 \mathrm{R}$ activates RhoA and reorganizes the cytoskeleton in a manner that permits stimulation of downstream signaling pathways, and (b) RhoA is a component of the IL-1R signaling complex. RhoA coprecipitated with both recombinant and native IL-1R, and a constitutively active form of RhoA directly interacted with the cytosolic domain of IL-1R in a filter-binding assay. The physical interactions between IL-1R and RhoA are functionally important. Inhibition of RhoA function by cellular incorporation of C 3 transferase not only prevented IL-1-mediated stress fiber formation in HeLa cells, but also blocked recruitment and/or activation of IL-1R-associated MBP kinases. In addition, dominant-negative RhoA abolished IL$1 \mathrm{Rcd}-$ dependent IL- 6 gene transcription. We have also found that Rac-1 coprecipitates with recombinant IL-1Rcd and was necessary for IL-6 transcription. Taken together, Rho family GTPases appear to integrate information from both cell-matrix contacts and IL-1R to facilitate downstream signaling and gene transcription for cell activation.

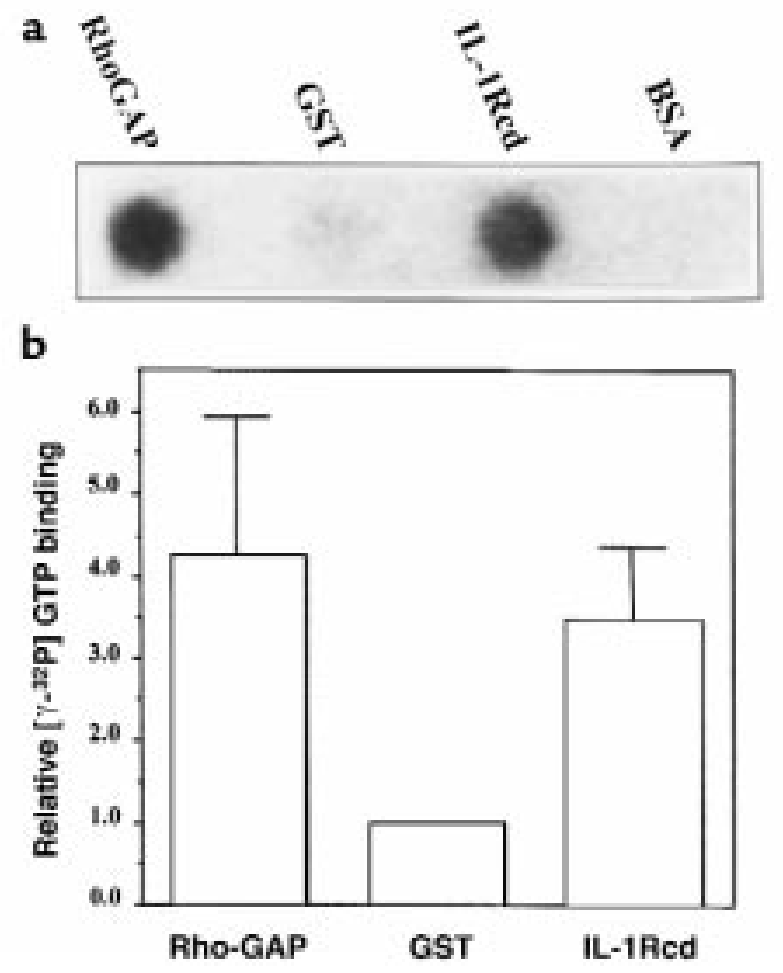

Figure 6

GST-IL-1 Rcd interacts directly with GTP-loaded V14RhoA in a filter-binding assay. GST, GST fusion proteins (GST-RhoGAP and GST-IL-1Rcd), and BSA were spotted on nitrocellulose and probed with $[\gamma-$ $\left.{ }^{32} \mathrm{P}\right] \mathrm{GTP}-$ loaded V14RhoA as described in Methods. Interacting proteins are viewed by autoradiography. The results shown are representative of 7 independent experiments. (a) $\left[\gamma^{3}{ }^{32} \mathrm{P}\right] \mathrm{GTP}-\mathrm{V} 14 \mathrm{RhoA}$ specifically binds RhoGAP (positive control) and GST-IL-1Rcd, but not the negative controls GST and BSA. (b) $\left[\gamma^{-32 P}\right]$ GTP-RhoV14 bound to GST, GSTRhoGAP, and GST-IL-1Rcd was quantified by scintillation counting, and cpm bound to GST fusion proteins are normalized to those bound to GST in each of 7 independent experiments. Binding of $\left[\gamma^{-32}\right.$ P]GTPRhoV14 to BSA was not observed. 


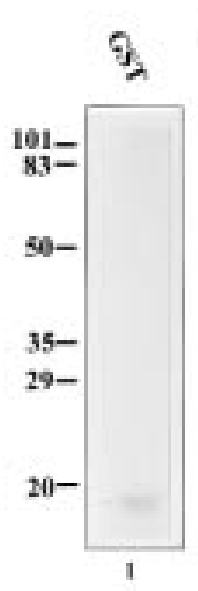

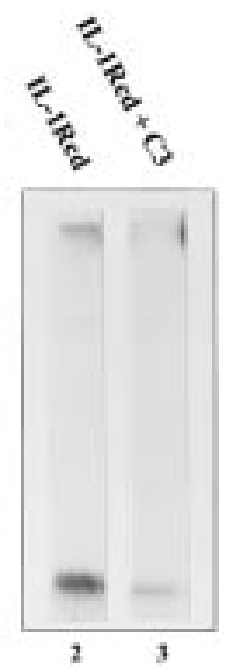

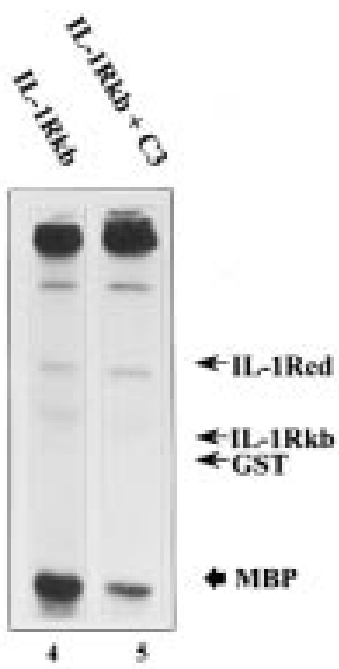

Figure 7

RhoA is required for assembly and activation of MBP kinases by IL-1Rcd. (a) Triton X-100 extracts were prepared from serum-deprived HeLa cells that had been treated with or without C3 transferase, and were incubated overnight with GST-IL-1Rcd fusion proteins. Fusion protein complexes were then assayed in solution for MBP kinase activity as described in Methods. Molecular mass markers (in kDa) are indicated at left, and the migration of GST and the GST-IL-1R fusion proteins, confirmed by Coomassie blue staining, is shown on the right. The autoradiogram is representative of 2 independent experiments. (b) HeLa cells were scrape-loaded in the presence $(+)$ or absence (-) of C 3 transferase. Extracts were prepared, and residual RhoA proteins available for ADP-ribosylation were determined using an in vitro reaction in the presence of C3 transferase, as described in Methods. Proteins were separated by SDS-PAGE, and [ $\left.{ }^{32} \mathrm{P}\right] \mathrm{NAD}$-labeled RhoA was viewed by autoradiography. Molecular mass markers are indicated at left, and migration of [ $\left.{ }^{32} \mathrm{P}\right]$ NAD-labeled RhoA proteins is indicated by the arrow on the right. (c) HeLa cell extracts were prepared from IL-1-stimulated cells that had been scrape-loaded in the absence $(-)$ or presence $(+)$ of C3 exoenzyme. MBP kinases associating with IL-1R immune complexes were identified by an in-gel kinase assay as described in Methods. Proteins were separated by SDS-PAGE and viewed by autoradiography. Molecular weight markers are indicated at left, and positions of the kinases p100, p83, and p63 are indicated on the right. IL-1R immunocomplexes coprecipitated 63-, 83-, and 100kDa MBP kinases, as we have reported previously (8). In contrast, no MBP kinase activity coprecipitated with IL-1R immunocomplexes from HeLa cells scrape-loaded with C3 transferase. The autoradiogram is representative of 2 independent experiments.

IL-1-dependent signal transduction is initiated by ligand-mediated association of IL-1R and IL-1RAcP through their extracellular domains. The cytoplasmic domains of both molecules are necessary for signaling. IL-1RAcP is necessary for stress kinase activation and IRAK activation. IRAK, a serine/threonine kinase that is recruited to the complex upon IL-1 stimulation, is necessary for NF- $\mathrm{KB}$ activation and coprecipitates with IL1RAcP (but not IL-1R) or a truncated form of IL-1RAcP lacking most of its intracellular domain $(6,7)$. Although IL-1R alone is insufficient to recruit IRAK, IL-1Rcd is necessary for both IL-1-stimulated signal transduction and gene transcription $(2,36-38)$. These data suggest that IL-1Rcd either provides contacts necessary for signaling-molecule recruitment (39) or recruits specific signaling molecules to the IL-1R heterocomplex. Consistent with the latter premise, both IRAK-2, a structural and functional homologue of IRAK, and the p85 subunit of phosphatidylinositol 3-kinase preferentially coprecipitate with IL-1R $(10,40)$. We have now shown, using a filter-binding assay, that IL-1Rcd sequences interact directly with an activated form of RhoA. A GSTIL-1R fusion protein containing the Toll domain (41), a region of IL-1Rcd essential for signal transduction, is sufficient to recruit Rho from HeLa cell lysates.

G-protein activities have previously been linked to IL1-activated signaling. IL-1-mediated stimulation of cyclic AMP production in a pre-B-cell line required a
GTPase activity that was sensitive to pertussis toxin (42). In thymoma cells, IL-1 increased $\left[{ }^{35} \mathrm{~S}\right] \mathrm{GTP} \gamma \mathrm{S}$ binding to cell membranes within 1 minute and concomitantly stimulated GTPase activity (23). However, these effects in thymoma cells could not be definitively linked to a pertussis toxin-sensitive $G$ protein, suggesting involvement of other $\mathrm{G}$ proteins in IL-1-activated signaling pathways. Similarly, GST-IL-1Rcd did not coprecipitate a pertussis toxin-sensitive GTPase activity (not shown). The Rho family GTPases Rac- 1 and Cdc 42 were subsequently shown to be necessary for IL-1-induced p38 activation, for the first time directly linking small-molecular-weight G proteins in IL-1 signaling pathways (43). RhoA has previously been shown to regulate the activities of both NF$\mathrm{KB}$ and JNK $(22,44)$, signaling molecules known to be stimulated by IL-1. Our data suggest that RhoA is a component of the IL-1R signaling complex. Interestingly, IL1 stimulates activity of phosphatidylinositol 3-kinase, a molecule that is regulated by Rho and which, like Rho (our data), physically associates with IL-1Rcd (40).

Mechanisms resulting in RhoA activation by extracellular stimuli are not well understood. In resting cells, RhoA localizes predominantly in cytosol as an inactive GDP-bound form complexed with a GDP dissociation inhibitor (45). However, even in unstimulated cells, a small fraction of RhoA localizes to the plasma membrane. In contrast to Ras, the interaction of RhoA with target proteins can be nucleotide independent. Both Rho 
Table 1

N19RhoA and N17Rac-1 block CAT activity stimulated by IL-1Rcd and directed by the IL-6 $5^{\prime}$ flanking region

$\begin{array}{lcc}\text { Expression construct } & \text { Inhibitor constructs } & \text { Relative CAT activity } \\ \text { pEBVHisLacZ } & \text { None } & 1.00 \\ & \text { PCMV5-N19RhoA } & 1.12 \pm 0.21 \\ & \text { pEXV-N17Rac-1 } & 1.08 \pm 0.22 \\ & & \\ \text { pEBVHisIL-1Rcd } & \text { None } & 2.67 \pm 0.25^{\mathrm{A}} \\ & \text { pCMV5-N19RhoA } & 0.94 \pm 0.10 \\ & \text { pEXV-N17Rac-1 } & 0.84 \pm 0.13\end{array}$

Human embryonic kidney 293 cells were transiently transfected with either a control mammalian expression plasmid ( $\mathrm{pEBVHisLacZ)} \mathrm{or} \mathrm{a} \mathrm{construct} \mathrm{containing} \mathrm{the}$ cytosolic domain of IL-1R ( $p$ EBVHisIL-1Rcd) and the IL-6 5' flanking region-CAT chimeric reporter plasmid, as described in Methods. In addition, the indicated Rho dominant-negative mutants were cotransfected, and CAT activity was assayed after 72 hours. Results are expressed as the CAT activity normalized to the CAT activity that was assayed in HeLa cells transfected with only pEBVHisLacZ. Results are expressed as the mean $\pm \operatorname{SEM}$ ( $n=3$ independent experiments). ${ }^{A} P<0.05$ compared with cells transfected with pEBVHisLacZ. Determined by Kruskall-Wallis one-way ANOVA, with pairwise comparisons by Dunn's method.

GDP and Rho GTP bind to phosphatidylinositol 4-phosphate kinase and the PRK2 kinase $(46,47)$. In addition, Rho has been coprecipitated with the PDGF- $\beta$ receptor (29) and IL-1R (our unpublished observations) in the absence of receptor activation. Since C3 transferase can ADP-ribosylate both PDGF- $\beta$ receptor- and IL-1R-associated Rho, Rho does not seem to interact with these molecules through its effector (switch 1) domain. Although Rho interactions with other proteins can be nucleotide independent, RhoA activity requires GDP to be replaced by GTP, with the help of a family of guanine nucleotide exchange factors (GEFs) (48). The IL-1-IL-1R interaction may activate Rho-dependent responses by increasing the levels of receptor-associated, GTP-bound RhoA through stimulation of GEFs or by inhibition of proteins that enhance GTP hydrolysis, such as RhoGAP. Taken together, our data suggest that RhoA may constitutively interact with IL-1Rcd but is only activated by IL1 stimulation of the target cells.

Small GTPases control fundamental cell properties including shape, differentiation, and motility by regulating cytoskeletal assembly and through interactions with multiple target proteins, $(21,48)$. In addition to soluble mediators in the microenvironment, adhesiondependent signals critically regulate these cell behaviors. Rho family GTPases control the assembly of both cellmatrix and cell-cell adhesion complexes, either directly by modification of their constituents or indirectly by organization of actin filaments into structures appropriate for complex formation $(33,35,49)$. Once assembled, adhesion complexes can control cell phenotype both by transmission of mechanical forces and by activation of signal transduction pathways. Integrin complexes are coupled to nuclear scaffold by cytoskeleton (50), raising the possibility that adhesion complexes can alter nuclear functions to switch cells between specific genetic programs. In addition, adhesion junctions control cell shape, or degree of spreading, which regulates cell growth responses (12) and may coordinate or constrain chemical signaling pathways (51).
Remodeling of matrix and alterations of cell-cell contacts in inflammation, with consequent cytoskeletal reorganization, may therefore permit cells to become activated by soluble signals in the microenvironment, such as IL-1. In fact, our data suggest that IL-1 actively reassembles the actin cytoskeleton to facilitate cytoplasmic and nuclear signaling. IL-1 binding increased the fraction of IL-1R sedimenting with cytoskeletal residues (52); and cytochalasin $\mathrm{D}$, which disrupts actin filaments, inhibited IL-1-stimulated increases in fibroblast cytosolic calcium (15). Plating fibroblasts on polyL-lysine prevented focal adhesion formation and prevented IL-1-stimulated calcium influx, extracellular signal-regulated kinase (ERK) activation, and c-fos expression $(19,53)$. IL-1 downregulated proteoglycan synthesis and stimulated IL- 6 gene expression in fibroblasts grown on fibronectin, but not on vitronectin or collagen, suggesting that specific matrix molecules regulate IL-1-activated signaling (18). Finally, IL1 -induced alterations in NF- $\mathrm{KB}$ and stress-activated protein kinase (SAPK) activities in cells grown on fibronectin were inhibited when cells were cultured on poly-L-lysine or when RGD-containing peptides were included (16). Rho family GTPases, by controlling adhesion complex assembly and consequent signaling activity, may function as molecular switches that cluster signaling molecules in specific architectures necessary for persistent cell activation (54).

In summary, we have demonstrated that RhoA physically associates with IL-1Rcd and is activated after binding of IL-1 to IL-1R. RhoA is required for IL-1-stimulated actin stress fiber formation, and appears to be necessary for the downstream signaling and gene transcription required for mesenchymal cell activation. Although stress fibers are not seen in vivo in normal tissue, there are marked alterations in the nature of adhesive contacts between cells and matrix proteins in inflamed and regenerating tissues in vivo. We propose that the extracellular matrix remodeling that is characteristic of inflammation alters adhesion complex function and cytoskeletal organization to permit cellular activation by soluble signals such as IL-1. Similar to their roles in morphogenesis, growth, and differentiation, Rho GTPases function as critical molecular switches that regulate cell behavior after inflammatory injury.

\section{Acknowledgments}

This work was supported by grants DK02281, DK38558, and P50DK54178 from the National Institute of Diabetes, Digestive and Kidney Diseases, and by a Grant-in-Aid from the American Heart Association. J.R. Schelling was the recipient of a Young Investigator Grant from the National Kidney Foundation and is an Established Investigator of the American Heart Association. The authors acknowledge the generous gifts of recombinant GST-RhoGAP and GST-V14RhoA from Alan Hall, and the expression construct containing dominant-negative RhoA from Martin A. Schwartz. The authors also thank Richard Chizzonite for the gift of recombinant human IL-1, and J. Vilcek for the gift of the IL-6 5' flanking region-CAT gene chimeric plasmid.

\footnotetext{
1. Dinarello, C.A. 1996. Biologic basis for interleukin-1 in disease. Blood. 87:2095-2147.

2.Heguy, A., Baldari, C.T., Macchia, G., Telford, J.L., and Melli, M. 1992.
} 
Amino acids conserved in interleukin-1 receptors (IL-1Rs) and the Drosophila toll protein are essential for IL-1R signal transduction. J. Biol. Chem. 267:2605-2609.

3. Kuno, K., Okamoto, S., Hirose, K., Murakami, S., and Matsushima, K. 1993. Structure and function of the intracellular portion of the mouse interleukin 1 receptor (type I). Determining the essential region for transducing signals to activate the interleukin 8 gene. J. Biol. Chem. 268:13510-13518.

4. Sims, J.E., et al. 1993. Interleukin 1 signaling occurs exclusively via the type I receptor. Proc. Natl. Acad. Sci. USA. 90:6155-6159.

5. Greenfeder, S.A., et al. 1995. Molecular cloning and characterization of a second subunit of the interleukin 1 receptor complex. J. Biol. Chem. 270:13757-13765.

6. Wesche, H., et al. 1997. The interleukin-1 receptor accessory protein is essential for IL-1-induced activation of interleukin-1 receptor-associated kinase (IRAK) and stress-activated kinases. J. Biol. Chem. 272:7727-7731.

7. Huang, J., Gao, X., Li, S., and Cao, Z. 1997. Recruitment of IRAK to the interleukin 1 receptor complex requires interleukin 1 receptor accessory protein. Proc. Natl. Acad. Sci. USA. 94:12829-12832.

8. Singh, R., Huang, S., Guth, T., Konieczkowski, M., and Sedor, J.R. 1997. Cytosolic domain of the type I interleukin-1 receptor spontaneously recruits signaling molecules to activate a proinflammatory gene. J. Clin. Invest. 100:419-428

9. Cao, Z., Henzel, W.J., and Gao, X. 1996. IRAK: a kinase associated with the interleukin-1 receptor. Science. 271:1128-1131.

10. Muzio, M., Ni, J., Feng, P., and Dixit, V.M. 1997. IRAK (Pelle) family member IRAK-2 and MyD88 as proximal mediators of IL-1 signaling. Science. 278:1612-1615.

11. Maniotis, A.J., Chen, C.S., and Ingber, D.E. 1997. Demonstration of mechanical connections between integrins, cytoskeletal filaments, and nucleoplasm that stabilize nuclear structure. Proc. Natl. Acad. Sci. USA. 94:849-854.

12. Chen, C.S., Mrksich, M., Huang, S., Whitesides, G.M., and Ingber, D.E. 1997. Geometric control of cell life and death. Science. 276:1425-1428.

13. Qwarnstrom, E.E., Page, R.C., Gillis, S., and Dower, S.K. 1988. Binding, internalization, and intracellular localization of interleukin-1 beta in human diploid fibroblasts. J. Biol. Chem. 263:8261-8269.

14. Qwarnström, E.E., MacFarlane, S.A., Page, R.C., and Dower, S.K. 1991 Interleukin-1 $\beta$ induces rapid phosphorylation and redistribution of talin: a possible mechanism for modulation of fibroblast focal adhesion. Proc. Natl. Acad. Sci. USA. 88:1232-1236.

15. Arora, P.D., Ma, J., Min, W., Cruz, T. , and McCulloch, C.A.G. 1995. Interleukin-1-induced calcium flux in human fibroblasts is mediated through focal adhesions. J. Biol. Chem. 270:6042-6049.

16. Zhu, P., Xiong, W., Rodgers, G., and Qwarnstrom, E.E. 1998. Regulation of interleukin 1 signalling through integrin binding and actin reorganization: disparate effects on NF-kappaB and stress kinase pathways. Biochem. J. 330:975-981.

17. Qwarnström, E.E., Ostberg, C.O., Turk, G.L., Richardson, C.A., and Bomsztyk, K. 1994. Fibronectin attachment activates the NF-kappaB $\mathrm{p} 50 / \mathrm{p} 65$ heterodimer in fibroblasts and smooth muscle cells. J. Biol. Chem. 269:30765-30768.

18. Ostberg, C.O., Zhu, P., Wight, T.N., and Qwarnstrom, E.E. 1995. Fibronectin attachment is permissive for IL-1 mediated gene regulation. FEBS Lett. 367:93-97.

19. Lo, Y.Y., Luo, L., McCulloch, C.A., and Cruz, T.F. 1998. Requirements of focal adhesions and calcium fluxes for interleukin-1-induced ERK kinase activation and c-fos expression in fibroblasts. J. Biol. Chem. 273:7059-7065.

20. Tapon, N., and Hall, A. 1997. Rho, Rac and Cdc42 GTPases regulate the organization of the actin cytoskeleton. Curr. Opin. Cell Biol. 9:86-92.

21. Hall, A. 1998. Rho GTPases and the actin cytoskeleton. Science. 279:509-514.

22. Montaner, S., Perona, R., Saniger, L., and Lacal, J.C. 1998. Multiple signalling pathways lead to the activation of the nuclear factor kappaB by the Rho family of GTPases. J. Biol. Chem. 273:12779-12785.

23. O'Neill, L.A., Bird, T.A., Gearing, A.J., and Saklatvala, J. 1990. Interleukin-1 signal transduction. Increased GTP binding and hydrolysis in membranes of a murine thymoma line (EL4). J. Biol. Chem. 265:3146-3152.

24. Malcolm, K.C., Elliott, C.M., and Exton, J.H. 1996. Evidence for Rho-mediated agonist stimulation of phospholipase $\mathrm{D}$ in rat 1 fibroblasts. Effects of Clostridium botulinum C3 exoenzyme. J. Biol. Chem. 271:13135-13139.

25. Morii, N., and Narumiya, S. 1995. Preparation of native and recombinant Clostridium botulinum C3 ADP-ribosyltransferase and identification of Rho proteins by ADP-ribosylation. Methods Enzymol. 256:196-206.

26. Laudanna, C., Campbell, J.J., and Butcher, E.C. 1996. Role of rho in chemoattractant-activated leukocyte adhesion through integrin. Science. 271:981-983.

27. Gronich, J., Konieczkowski, M., Gelb, M.H., Nemenoff, R.A., and Sedor, J.R. 1994. Interleukin $1 \alpha$ causes rapid activation of cytosolic phospholi- pase $\mathrm{A}_{2}$ by phosphorylation in rat mesangial cells. J. Clin. Invest. 93:1224-1233.

28. Self, A.J., and Hall, A. 1995. Purification of recombinant Rho/Rac/G25K from Escherichia coli. Methods Enzymol. 256:3-10.

29. Zubiaur, M., Sancho, J., Terhorst, C., and Faller, D.V. 1995. A small GTPbinding protein, Rho, associates with the platelet-derived growth factor type-beta receptor upon ligand binding. J. Biol. Chem. 270:17221-17228.

30. Diekmann, D., Nobes, C.D., Burbelo, P.D., Abo, A., and Hall, A. 1995. Rac GTPase interacts with GAPs and target proteins through multiple effector sites. EMBO J. 14:5297-5305.

31. Burbelo, P.D., Drechsel, D., and Hall, A. 1995. A conserved binding motif defines numerous candidate target proteins for both $\mathrm{Cdc} 42$ and $\mathrm{Rac}$ GTPases. J. Biol. Chem. 270:29071-29074.

32. Renshaw, M.W., Toksoz, D., and Schwartz, M.A. 1996. Involvement of the small GTPase rho in integrin-mediated activation of mitogen-activated protein kinase. J. Biol. Chem. 271:21691-21694.

33. Ridley, A.J., and Hall, A. 1992. The small GTP-binding protein rho regulates the assembly of focal adhesions and actin stress fibers in response to growth factors. Cell. 70:389-399.

34. Ren, X.D., Kiosses, W.B., and Schwartz, M.A. 1999. Regulation of the small GTP-binding protein Rho by cell adhesion and the cytoskeleton. EMBO J. 18:578-585.

35. Nobes, C.D., and Hall, A. 1995. Rho, rac, and cdc42 GTPases regulate the assembly of multimolecular focal complexes associated with actin stress fibers, lamellipodia, and filopodia. Cell. 81:53-62.

36. Curtis, B.M., et al. 1989. T-cell interleukin 1 receptor cDNA expressed in Chinese hamster ovary cells regulates functional responses to interleukin 1. Proc. Natl. Acad. Sci. USA. 86:3045-3049.

37. Leung, K., Betts, J.C., Xu, L., and Nabel, G.J. 1994. The cytoplasmic domain of the interleukin-1 receptor is required for nuclear factor- $\kappa \mathrm{B}$ signal transduction. J. Biol. Chem. 269:1579-1582.

38. Croston, G.E., Cao, Z., and Goeddel, D.V. 1995. NF-kB activation by interleukin-1 requires an IL-1 receptor-associated protein kinase activity. J. Biol. Chem. 270:16514-16517.

39. Burns, K., et al. 1998. MyD88, an adapter protein involved in interleukin1 signaling. J. Biol. Chem. 273:12203-12209.

40. Reddy, S.A., Huang, J.H., and Liao, W.S. 1997. Phosphatidylinositol 3kinase in interleukin 1 signaling. Physical interaction with the interleukin 1 receptor and requirement in NFkappaB and AP-1 activation. J. Biol. Chem. 272:29167-29173.

41. Mitcham, J.L., et al. 1996. T1/ST2 signaling establishes it as a member of an expanding interleukin-1 receptor family. J. Biol. Chem. 271:5777-5783.

42. Chedid, M., Shirakawa, F., Naylor, P., and Mizel, S.B. 1989. Signal transduction pathway for IL-1. Involvement of a pertussis toxin-sensitive GTP-binding protein in the activation of adenylate cyclase. J. Immunol. 142:4301-4306.

43. Zhang, S., et al. 1995. Rho family GTPases regulate p38 mitogen-activated protein kinase through the downstream mediator Pak1. J. Biol. Chem. 270:23934-23936.

44. Teramoto, H., et al. 1996. The small GTP-binding protein Rho activates c-Jun N-terminal kinases stress-activated protein kinases in human kidney 293 T cells: evidence for a Pak-independent signaling pathway. J. Biol. Chem. 271:25731-25734.

45. Somlyo, A.P. 1997. Signal transduction. Rhomantic interludes raise blood pressure. Nature. 389:908-909.

46. Vincent, S., and Settleman, J. 1997. The PRK2 kinase is a potential effector target of both Rho and Rac GTPases and regulates actin cytoskeletal organization. Mol. Cell. Biol. 17:2247-2256.

47. Ren, X.D., et al. 1996. Physical association of the small GTPase Rho with a 68-kDa phosphatidylinositol 4-phosphate 5-kinase in Swiss 3T3 cells. Mol. Biol. Cell. 7:435-442.

48. Hall, A. 1998. G proteins and small GTPases: distant relatives keep in touch. Science. 280:2074-2075.

49. Braga, V.M., Machesky, L.M., Hall, A., and Hotchin, N.A. 1997. The small GTPases Rho and Rac are required for the establishment of cadherindependent cell-cell contacts. J. Cell Biol. 137:1421-1431.

50. Maniotis, A.J., Bojanowski, K., and Ingber, D.E. 1997. Mechanical continuity and reversible chromosome disassembly within intact genomes removed from living cells. J. Cell. Biochem. 65:114-130.

51. Kheradmand, F., Werner, E., Tremble, P., Symons, M., and Werb, Z. 1998. Role of Rac1 and oxygen radicals in collagenase- 1 expression induced by cell shape change. Science. 280:898-902.

52. Guo, C.M., Georgiadis, K.E., Dower, S.K., Holowka, D., and Baird, B.A. 1999. Interleukin 1 (IL-1) causes changes in lateral and rotational mobilities of LL-1 type I receptors. Biochemistry. 38:1618-1625.

53. Luo, L., Cruz, T., and McCulloch, C.A. 1997. Interleukin 1-induced calcium signalling in chondrocytes requires focal adhesions. Biochem. J. 324:653-658

54. Penninger, J.M., and Crabtree, G.R. 1999. The actin cytoskeleton and lymphocyte activation. Cell. 96:9-12. 